\title{
Asymmetric segregation on spindle poles of the Schizosaccharomyces pombe septum-inducing protein kinase Cdc7p
}

\author{
Marc Sohmann, ${ }^{1}$ Susanne Schmidt, ${ }^{1}$ Iain Hagan, ${ }^{2}$ and Viesturs Simanis ${ }^{1,3}$ \\ ${ }^{1}$ Cell Cycle Control Laboratory, Swiss Institute for Experimental Cancer Research (ISREC), 1066 Epalinges, Switzerland; \\ ${ }^{2}$ School of Biological Sciences, University of Manchester, Manchester M 13 9PT, UK
}

\begin{abstract}
Schizosaccharomyces pombe divides by means of a centrally placed division septum. The initiation of septation must be tightly coordinated with events in mitosis, as premature formation of the septum can lethally cut the undivided nucleus. The Spglp GTPase and the Cdc7p kinase, with which it interacts, play a central role in signaling the initiation of septum formation. Loss-of-function mutations in either gene prevent septation, whereas inappropriate activation of Spglp can induce septum formation from $G_{1}$ or $G_{2}$ interphase cells. Increased expression of either gene leads to multiple rounds of septation without cell cleavage, emphasizing the need for precise cell cycle regulation of their activity. To understand the mechanisms underlying this regulation, we have investigated whether these key initiators of septum formation are controlled by changes in their activity and/or location during mitosis and cytokinesis. We demonstrate that Spglp localizes to the spindle pole body in interphase and to both spindle poles during mitosis. In contrast, Cdc7p shows no discrete localization during interphase, but early in mitosis it associates with both spindle pole bodies and, as the spindle extends, is seen on only one pole of the spindle during anaphase B. Spglp activity is required for localization of Cdc7p in vivo but not for its kinase activity in vitro. Staining with an antiserum that recognizes preferentially GDP-Spglp indicates that activated GTP-Spglp predominates during mitosis when Cdc7p is associated with the spindle pole body. Furthermore, staining with this antibody shows that asymmetric distribution of Cdc7p may be mediated by inactivation of Spglp on one spindle pole Deregulated septation in mutant cells correlates with segregation of Cdc7p to both spindle poles.
\end{abstract}

[Key Words: Mitosis; spindle pole body; cytokinesis; kinase; GTPase]

Received July 30, 1997; revised version accepted October 20, 1997.

Schizosaccharomyces pombe cells grow mainly by elongation at their tips, then divide by formation of a centrally placed septum to produce daughter cells of approximately equal size. The position of the division septum is defined early in mitosis, but its synthesis is not initiated until the end of mitosis, when the daughter nuclei are well separated from each other and the spindle begins to break down. The onset of septum formation must be properly coordinated with mitosis. If septum formation occurs before mitosis is completed, the nucleus may be "cut" by the developing septum (see, e.g., Hirano et al. 1986).

The main morphological events of septum formation and cytokinesis in fission yeast have been reviewed (Robinow and Hyams 1989). As in higher eukaryotes, the fission yeast cytoskel eton undergoes a characteristic series of rearrangements during mitosis and cytokinesis. In interphase cells, a basket of microtubules runs from end to end in the cell (Hagan and Hyams 1988). At the onset

${ }^{3}$ Corresponding author.

E-MAIL viesturs.simanis@isrec.unil.ch; FAX +41-21-652-6933. of mitosis, the cytoplasmic microtubule array is repl aced by a short intranuclear spindle, which elongates as mitosis proceeds. As in higher eukaryotes, spindle formation in S. pombe occurs by interdigitation of two microtubule arrays extending from the dupl icated spindl e pole bodies (the functional equivalent of the mammalian centrosome), which span the nuclear membrane. The spindle breaks down at the end of mitosis, to be replaced by a new interphase array that is seeded from microtubule-organizing centres (MTOCs) at the cell equator (Hagan and Hyams 1988; for review, see Hagan et al. 1997).

The distribution of F-actin in S. pombe cells is intimately linked with sites of growth or septum formation. During interphase, F-actin is observed mainly as cortical patches at the growing ends of the cell, though actin cables can al so be seen (M arks and Hyams 1985; Balasubramanian et al. 1996). At the onset of mitosis, a medial F-actin-containing ring is formed at the site where the septum will be synthesized later (for review, see Gould and Simanis 1997). F-actin patches are subsequently polarized to this ring, and the cell is thus primed for sep- 
tation. At the end of anaphase, the primary septum grows inward from the cell cortex. Secondary septa are formed on either side of the primary septum, which is dissolved to effect cell separation. F-actin patches are then relocated to the old (preexisting) end of the cell, where growth resumes.

Because the position of the division site is determined early in mitosis (Chang et al. 1996), the temporal coordination of mitotic events with septum formation is likely to be mediated through the proteins that trigger septum biosynthesis. The products of the cdcll (N urse et al . 1976), cdc14 (Fankhauser and Simanis 1993), cdc7 (Fankhauser and Simanis 1994), plol (Ohkura et al. 1995), and spgl genes (Schmidt et al. 1997) are all essential for initiating septation, whereas loss of either cdc16 or byr4 activity deregulates septation, resulting in multiple rounds of septum formation without cell cleavage (Minet et al. 1979; Fankhauser et al. 1993; Song et al. 1996). Increased expression of Plolp or Spglp will induce septation in either $\mathrm{G}_{1}$ - or $\mathrm{G}_{2}$-arrested interphase cells (Ohkura et al. 1995; Schmidt et al. 1997). M oderate-level expression of Cdc7p prevents septum formation from being turned off but does not induce septation from $\mathrm{G}_{2}$ arrested cells (Fankhauser and Simanis 1994). The cdc7 gene encodes a protein kinase, whereas Spglp is a GTPase of the Ras superfamily. The two proteins have been shown to interact, and the induction of septum formation by Spglp requires functional Cdc7p (Schmidt et al . 1997). In this study we have investigated the biological role of the interaction of Spglp and Cdc7p. We show that Spglp is associated with the spindle pole body throughout the cell cycle. Activation of Spglp is required for Cdc7p to associate with the spindle pole body early in mitosis, from where it signals the onset of septum formation at the end of mitosis. In contrast to all other spindle pole body markers examined to date, Cdc7p is distributed asymmetrically to one of the two poles in late anaphase. The implications of these unexpected results for regulation of septum formation are discussed.

\section{Results}

Cdc7p kinase activity does not require Spglp function

Because C dc 7p kinase activity is required for the onset of septum formation (Fankhauser and Simanis 1994), we assayed its activity in a synchronized population of cells generated by arrest-release of a cdc25-22 mutant (Figure 1A). This demonstrated that the steady-state level of Cdc7p (Fig. 1B,C), and its kinase activity (Fig. 1D,E) were similar in extracts prepared from cells in $\mathrm{G}_{2}$, mitosis, or at the time of septum formation. We conclude that Cdc7p has the potential to be active at all stages of the cell cycle.

We also examined whether Cdc7p kinase activity is affected by mutation of proteins that are implicated in the regulation of septum formation. Cdc7p kinase assays were performed on protein extracts prepared from the spg1-B8 mutant, which fails to form the division septum, and cdc16-116, which undergoes repeated rounds of

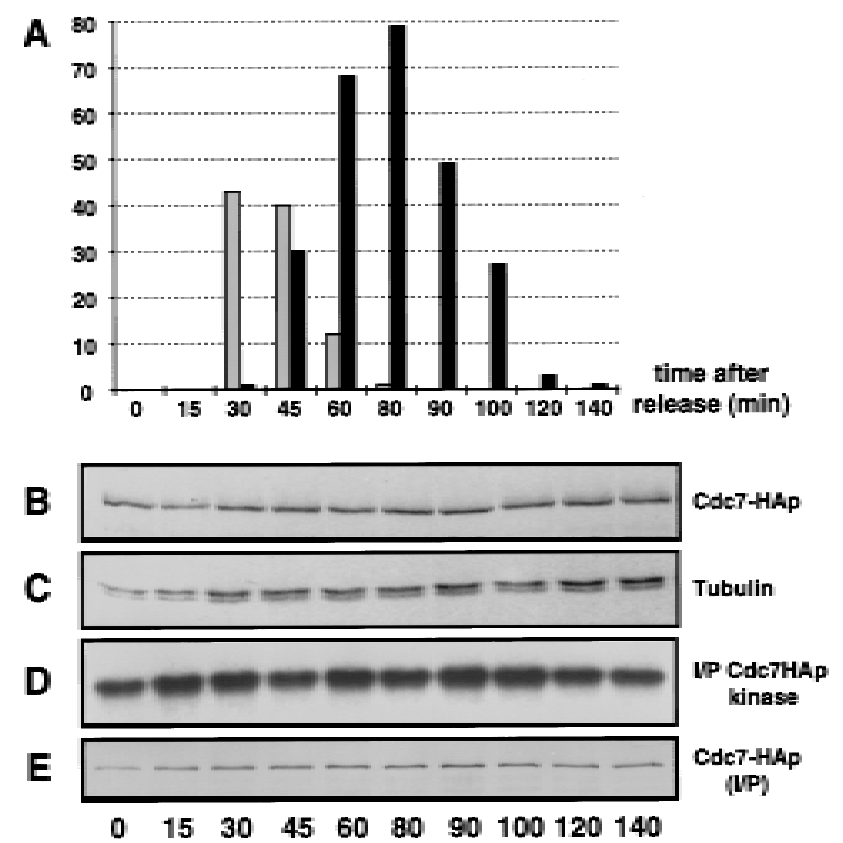

Figure 1. The steady-state level and in vitro kinase activity of Cdc7p do not change significantly as cells proceed from interphase through mitosis, septum formation, and cytokinesis. Cells were synchronized by arrest-rel ease of cdc25-22 cdc7-HA as described in Materials and Methods. Protein samples were prepared at intervals. The number of cells that were in mitosis or forming a division septum at each time point was determined. (A) The percentage of cells in anaphase (shaded bar), and forming a division septum (solid bar) at each time point; (B) Western bl ot of total protein extracts, probed with mA $12 C A 5$; (C) the same samples as in B, probed with TAT-1 as loading control; (D) kinase activity of Cdc7p, assayed using myel in basic protein as substrate; (E) Western blot of Cdc7-HAp in the immunoprecipitates used in $\mathrm{D}$, using mAb 12CA5.

septum formation. The activity of C dc7p in these mutant backgrounds did not vary significantly, whether the extracts were prepared from cells grown at permissive or restrictive temperature (Fig. 2A, cf. assays from each mutant, at $25^{\circ} \mathrm{C}$ or $36^{\circ} \mathrm{C}$ ). Thus, loss of Spglp or Cdc16p function does not affect $\mathrm{Cdc} 7 \mathrm{p}$ kinase activity in vitro.

\section{Cdc7p interacts preferentially with GTP-Spglp}

Our previous studies have demonstrated that Spglp and Cdc7p bind to each other and that mutations in the effector domain of Spglp interfere with the interaction: It was also proposed that the GTP-bound form of Spglp was the biologically active form (Schmidt et al. 1997). We therefore tested whether Spglp binding to GDP or GTP affected its interaction with Cdc7p. A GST-Spglp fusion protein was expressed in Escherichia coli. The purified protein was stabilized in the GDP- or GTPbound form and mixed with protein extracts from wildtype S. pombe cells, and proteins binding to Spglp were recovered by affinity chromatography on glutathioneagarose columns. Western blot analysis showed that 
Figure 2. $C d c 7 p$ binds to the GTP-bound form of Spglp, which is not recognized by the anti-Spglp antiserum (SuSu1). (A) Cells carrying the cdc7-HA allele in a wild-type, spg1-B8, or cdc16-116 background were grown in YE medium at $25^{\circ} \mathrm{C}$. Half the culture was shifted to $36^{\circ} \mathrm{C}$ for $4 \mathrm{hr}$. Protein extracts were prepared and Cdc7p was immunoprecipitated with the anti-Cdc7p antiserum. The kinase activity associated with the precipitate was assayed using myelin basic protein as in vitro substrate (performed at $25^{\circ} \mathrm{C}$ or $36^{\circ} \mathrm{C}$, respectively). The amount of protein in the immunoprecipitates was analyzed by Western blotting with mAb 12CA5. (B) GST, the GDP-, or the GTP-bound form of GST-Spglp were mixed with protein extracts prepared from wild-type (972) or cdc7-HA cells. The complexes precipitated with glutathione-agarose were Western blotted and probed with anti-Spglp antiserum (SuSul) and mAb 12CA5. (C) Total proteins were prepared from wild-type (972) and spgl-HA cells. The Western blot was probed with a mix-

ture of TAT-1 (loading control) and mAb 12CA5. (D) Proteins were prepared from spg1-HA cells in the absence (top) or presence (bottom) of GTP $\gamma$ S, and Spgl-HAp was immunopreci pitated with mAb 12CA5. The soluble extracts and the immunopreci pitates were analyzed by Western blotting with mAb 12CA5. N ote that equal amounts of Spg1-HAp are immunoprecipitated in the presence or absence of GTP $\gamma$ S. (E) Same as in D, except that proteins were prepared from wild-type cells (972), and the anti-Spglp antibody (SuSu1) was used for immunoprecipitation and Western blotting. $\mathrm{N}$ ote that much less protein is precipitated by this serum in the presence of GTP $\gamma$ S, suggesting that the antibody recognizes preferentially GDP-Spglp.

Cdc7p was recovered much more efficiently by the GTPbound form of Spglp (Fig. 2B).

Spglp is associated with the spindle pole body throughout the mitotic cell cycle

The data described above suggest that regulation of the onset of septation may be mediated by controlling the location of C dc7p, the availability of substrate, or both. To pursue this idea further, we examined the localization of Cdc7p and Spglp through the cell cycle. To local ize Spglp, the influenza hemagglutinin (HA) epitope tag, recognized by the $12 \mathrm{CA} 5$ monoclonal antibody, was added to the carboxyl terminus of Spglp (Spgl-HAp) by modifying the chromosomal copy of the spgl gene (Fig. $2 \mathrm{C}$; see $\mathrm{M}$ aterial and $\mathrm{M}$ ethods). Indirect immunofluorescence using $\mathrm{mAb} 12 \mathrm{CA} 5$ showed that Spg1-HAp associated with the spindle pole body throughout the cell cycle (Fig. 3A,C). Spglp staining colocalized with the spindle pole body marker Sad1p during interphase and mitosis (Fig. 4A, Hagan and Yanagida 1995). Staining for Sad1p (data not shown) and microtubules (Schmidt et al. 1997) did not reveal any mitotic defects in the spgl null allele, indicating that Spglp is not an essential structural component of the spindle pole body.

Cdc7p is located on both spindle pole bodies early in mitosis and one spindle pole body late in mitosis

Cdc7p was detected using a polyclonal antibody raised against a region carboxy-terminal to the catalytic domain (Fankhauser and Simanis 1994). In mitotic cells with a short spindle, C dc7p associated with both spindle pole bodies (Fig. 3B, cells 2 and 3). After initiation of anaphase $B, C \mathrm{dc} 7 \mathrm{p}$ immunofluorescence was observed on only one of the two spindle poles (Fig. 3B, cell 4, and Figs. $3 \mathrm{C}$ and $4 \mathrm{~B}$ ), and this asymmetry persisted in cells that were forming a division septum (Fig. 3B, cell 5). Despite the fact that the steady-state level of Cdc7p was constant during interphase, mitosis, and cytokinesis (Fig. 1B), no discrete Cdc7p staining was seen either in cells that had completed the septum (Fig. 3B, cell 6), or in interphase cells (Fig. 3B, cell 1). N o discrete C dc7p staining was detected in cells arrested in late $\mathrm{G}_{2}$ by the cdc 25 22 mutation (data not shown), indicating that association of $\mathrm{Cdc} 7 \mathrm{p}$ with the spindle pole body depends on entry into mitosis.

To exclude the possibility that the $C \mathrm{dc} 7 \mathrm{p}$ epitopes recognized by the polycl onal serum were masked on one of the two poles, we used strains in which the chromosomal copy of the cdc7 gene had been replaced with a modified version, tagging $C d c 7 p$ at its carboxyl terminus with either the HA epitope (cdc7-HA cells; Schmidt et al. 1997) or green fluorescent protein (cdc7-GFP; this study). Indirect immunofluorescence using mA b 12CA 5 (Fig. 7D, bel ow) and observation of the Cdc7p-GFP fluorescence (Fig. 3D) confirmed the asymmetric association of C $\mathrm{dc} 7 \mathrm{p}$ with one spindl e pole. Using the birth scar as a morphological marker for asymmetry (Mitchison and N urse 1985), no significant bias in segregation of Cdc7p 


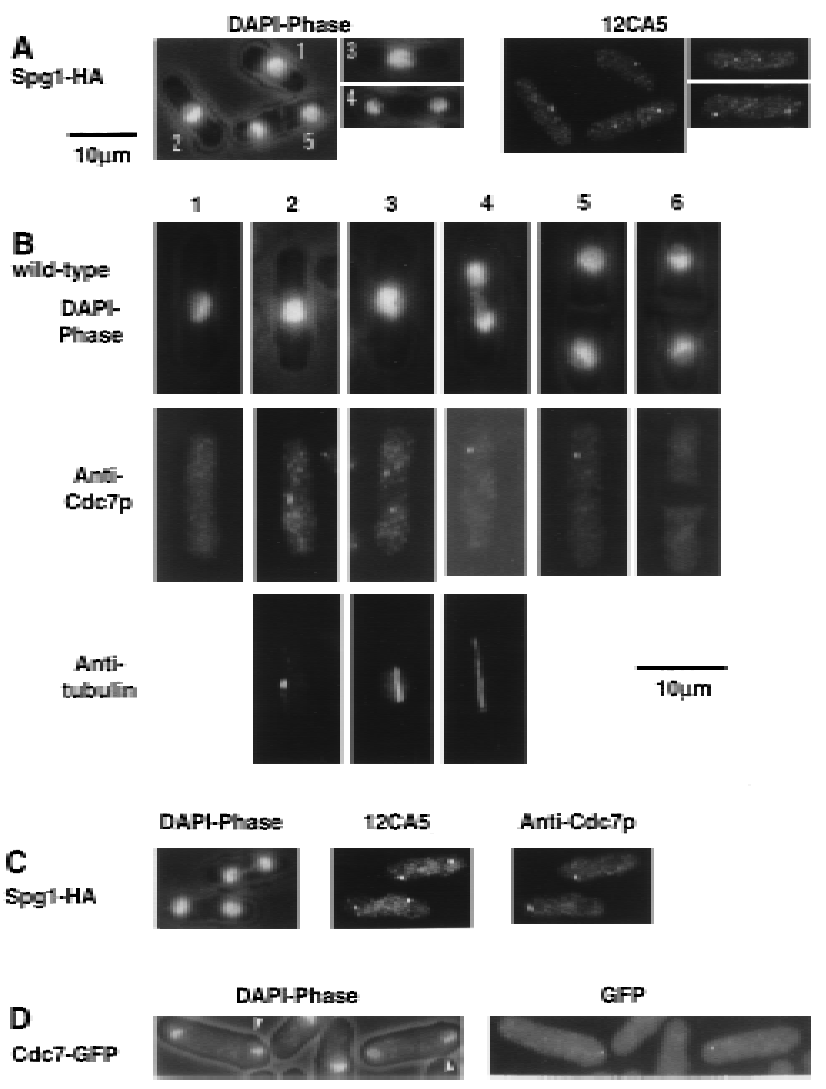

Figure 3. Localization of C dc7p and Spglp to the spindle pole body. Cells from the indicated strains were grown at $25^{\circ} \mathrm{C}$ in $Y E$, fixed, and stained, using the indicated antibodies. DAPI shows the DNA, and phase contrast shows the cell outline. (A) spg1-HA cells stained with mA b 12CA5. Cell 1 is in interphase; in cell 2, the two spindle pole bodies have started to separate; cell 3 is in early anaphase; cell 4 is in late anaphase; and cell 5 has formed the division septum. (B) Wild-type cells (972), stained with anti-Cdc7p antibodies and TAT-1. Cell-cycle stages are indicated in the text. (C) Mitotic spgl-HA cells, stained with $\mathrm{mAb} 12 \mathrm{CA} 5$ and anti-Cdc7p antibodies. (D) cdc7GFP fluorescence in mitotic cells. The arrows indicate the position of the birth scars.

to the old or new end of the cell was observed (Fig. 3D). We do not know what percentage of the total amount of Cdc7p is associated with the spindle pole body. Therefore, at present, we cannot say whether the asymmetric pattern of $\mathrm{Cdc} 7 \mathrm{p}$ local ization means that only one of the two daughter cells inherits Cdc7p. The location of C dc7p during interphase is unknown, but it is possible that the absence of a discrete staining pattern in interphase cells reflects a diffuse cytoplasmic staining that falls below the limit of detection.

We were concerned about the possibility that C $d c 7 p$ staining associated with microtubules, the medial ring, or equatorial MTOCs might fall below the limit of detection. We therefore stained cells expressing a level of Cdc7p $\sim 20$-fold higher than normal from a multicopy plasmid. Although we observed an increase in cytoplasmic staining, no medial ring, microtubule, or equatorial MTOC staining was seen under these conditions, sug- gesting that $C \mathrm{dc} 7 \mathrm{p}$ does not normally associate with these structures (data not shown). Formally, we cannot exclude the possibility that the number of binding sites for C dc7p at these locations is limited, precluding its detection with our current reagents; however, we feel that our combined genetic and cytological observations make this interpretation unlikely.

Localization of Cdc7p to the spindle pole body requires Spglp function, but not vice versa

GTPase-mediated local ization of kinases to their sites of action is an emerging theme in the function of signal transduction systems (e.g., Hall 1994; Mochley-Rosen 1995; Peter et al. 1996; Leberer et al. 1997). Because functi onal Spglp is not requi red for C dc7p kinase activity, we examined the effects of cdc7 and spgl mutations upon localization of Spglp and Cdc7p. No discrete Cdc7p staining was detected during mitosis in cells arising from germination of spgl null allele spores, or in spg1-B8 cells incubated at restrictive temperature (Fig. 5A). Therefore, Spglp activity is required to localize Cdc7p to the spindle pole body. In cells del eted for the cdc7 gene (Fig. 5B), and the cdc7-24 mutant (data not shown), Spglp
A
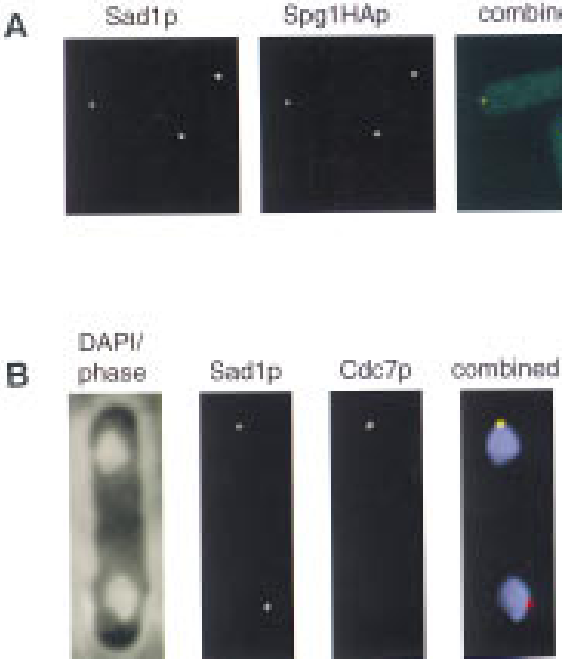

Figure 4. Cdc7p and Spglp colocalize with the spindle pole body component Sadlp. (A) spg1-HA cells were stained with anti-Sad1p antibodies and mAb 12CA5. Background fluorescence from secondary antibodies was used to show the cell outline. The lower cell is in interphase; the upper cell is undergoing anaphase. Sad1p was detected with FITC-conjugated secondary antibody, which gives green fluorescence, and Cdc7p was detected with CY3-conjugated secondary antibody, which gives red fluorescence. Colocal ization of green and red gives a yellow color, that is seen in the merged image. The individual channels are shown in gray tones, the merged image is in color. (B) Wildtype cells were stained with DAPI, anti-Sadlp (raised in sheep), and anti-Cdc7p antibodies. A mitotic cell is shown. In the combined image, DAPI is shown in violet, Sadlp gives red fluorescence, and Cdc7p gives green fluorescence. Colocalization of Sadlp and Cdc7p on one pole results in yellow (see A) color. 
A
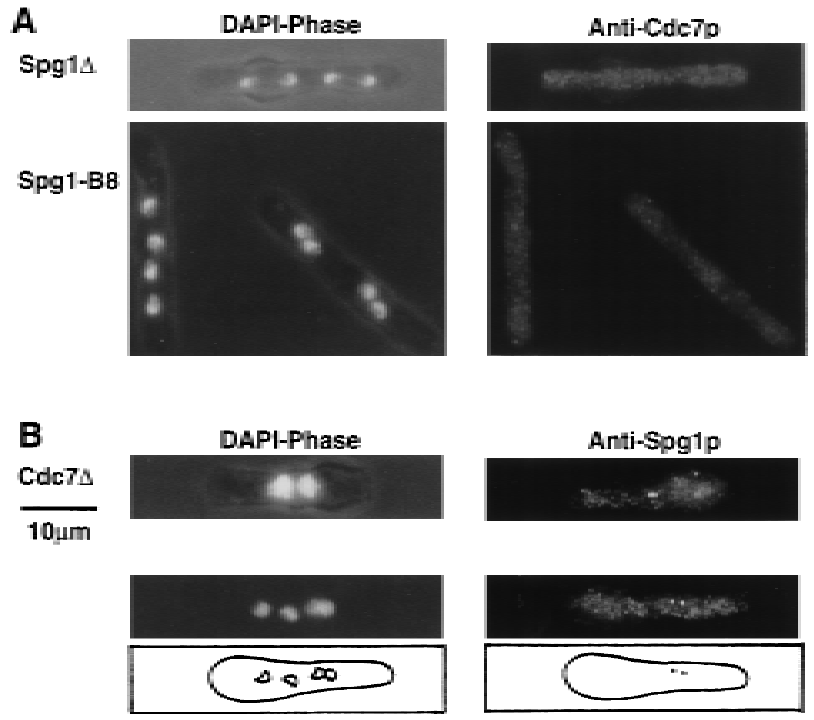

Figure 5. Spindle pole body localization of $C d c 7 p$ requires Spglp, but correct localization of Spglp occurs in the absence of Cdc7p. spgl-B8 cells were grown at $25^{\circ} \mathrm{C}$ and shifted for $4 \mathrm{hr}$ to $36^{\circ} \mathrm{C}$ before fixation. Spores del eted for spgl or cdc7 were germinated in minimal medium containing supplements al lowing only spores carrying the null allele to germinate (described in Materials and Methods). (A) spgl null allele (top) and spgl-B8 (bottom) cells were stained with anti-Cdc7p antibodies (only mitotic cells are shown). (B) cdc7 null cells stained with antiSpglp antibodies (SuSu1). The top panels show a binucleate interphase cell; the bottom panels show a cell undergoing the second mitosis. The positions of the nuclei and the spindle pole bodies in the mitotic cell are schematically represented. N ote that the right nuclei of each segregating pair almost colocalize. Spindle pole body-mediated clustering of nuclei is often observed in cdc7 mutants (for a detailed description of nuclear positioning in fission yeast, see Hagan and Yanagida 1997).

localized to the spindle pole body in both interphase and mitosis [note that the signal is asymmetric in mitotic cells because of the use of a polyclonal antiserum recognizing preferentially GDP-Spglp (SuSu1; see below)]. Thus, Cdc7p is not required for correct localization of Spglp. Depolymerization of microtubules by cold shock (Hagan and Yanagi da 1995) and staining of the $\beta$-tubul in mutant nda3-KM311 (Hiraoka et al . 1984) showed that spindle pole body localization of Cdc7p and Spglp is independent of microtubule integrity (data not shown).

Deregulated septum formation correlates with symmetrical distribution of Cdc7p during mitosis

Because $C d c 7 p$ al ways segregates to only one pole of the spindle in late anaphase in wild-type cells, we examined whether this was the case in cells where septum formation is deregulated. It has been proposed that the cdc16 gene product encodes the GTPase-activating protein (GAP) of Spglp (Boguski and McCormick 1993; Schmidt et al. 1997). Consistent with this, the multiseptate phenotype resulting from loss of cdc16 function resembles that produced by increased expression of Spglp and
Cdc7p (Mineti et al. 1979; Fankhauser et al. 1993; Fankhauser and Simanis 1994; Schmidt et al. 1997). cdc16-116 cells grown at restrictive temperature were stained with the anti-Cdc7p antiserum. Cdc7p was seen to associate with both spindle pole bodies throughout anaphase and septum formation (Fig. 6A), in contrast to wild-type cells, where Cdc7p was associated with only one pole of late anaphase spindles. Spglp was also present on both poles (Fig. 6B). The same results were obtained when the experiment was repeated using germinating spores deleted for the cdc16 gene (data not shown). Cells in which septum formation is deregulated by increased expression of Spglp (Fig. 6C), and cells overexpressing Cdc $7 p$ (data not shown), al so showed a bi polar distribution of $\mathrm{Cdc} 7 \mathrm{p}$ in mitotic cells, confirming the correlation between the symmetric segregation of $\mathrm{Cdc} 7 \mathrm{p}$ at mitosis and deregulation of septum formation. C dc $7 p$ was also located on the spindle pole in septated, mononucleate cells induced by increased expression of Spglp (Fig. 6C, Schmidt et al. 1997). Thus, in wild-type cells Cdc7p is associated with only one spindle pole in late anaphase, whereas deregulation of septum biosynthesis correlates with association of Cdc7p with both poles of the spindle throughout mitosis and septum formation. The potential significance of this is addressed in the Discussion.

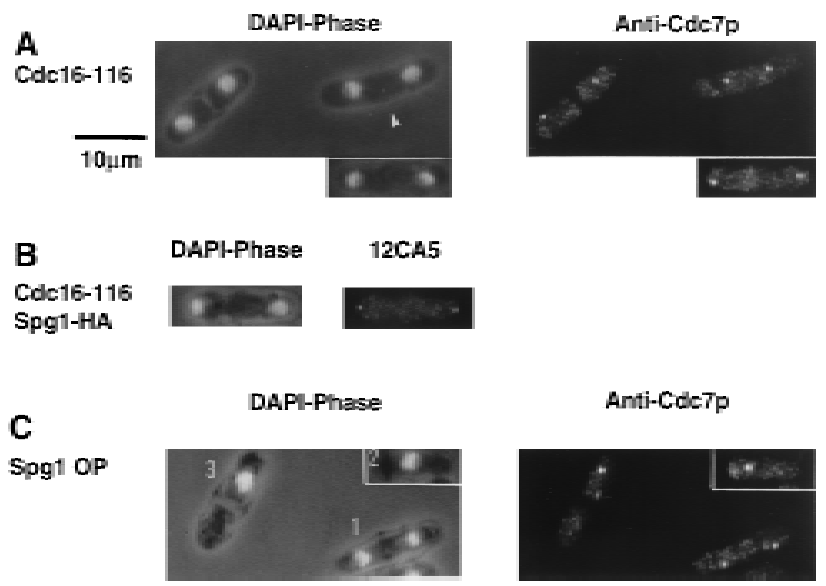

Figure 6. Loss of Cdc16p function results in segregation of Cdc7p to both poles of the mitotic spindle. cdc16-116 cells were shifted from $25^{\circ} \mathrm{C}$ to $32^{\circ} \mathrm{C}$ for $1.5 \mathrm{hr}$ before fixation. Cells were prepared for immunofluorescence and stained using the indicated antibodies. DAPI shows the DNA; phase contrast shows the cell outline. (A) cdc16-116 cells stained with anti-Cdc7p antibodies. $\mathrm{N}$ ote that the cell marked with an arrowhead has completed anaphase and that the spindle pole bodies guide the movement of the nuclei toward the center of the future daughter cells (Hagan and Yanagida 1997). (B) cdc16-116 spg1-HA cell, stained with mAb 12CA5. (C) Cells overexpressing Spglp (induced for $18 \mathrm{hr}$ at $25^{\circ} \mathrm{C}$ from the nmt1 promotor SP1805; Schmidt et al. 1997), stained with anti-Cdc7p antibodies. Cell 1 is undergoing anaphase and shows symmetrical C $\mathrm{dc} 7 \mathrm{p}$ staining; cell 2 is in interphase and has C dc7p associated with the spindle pole body; cell 3 has Cdc7p associated with the spindle pole body and initiated septum formation during interphase. 
Inactivation of Spglp on one of the two spindle poles may mediate the asymmetric distribution of C dc7p

Two reagents recognizing Spglp were available: mAb 12CA5 recognizing Spgl-HAp, and an antiserum raised against the carboxy-terminal 19 amino acids of Spglp (hereafter referred to as SuSu1; Schmidt et al. 1997). We tested whether these antibodies differed in their ability to recognize the GDP- and GTP-bound forms of Spglp. Protein extracts from wild-type or spgl-HA cells were prepared in the presence or absence of GTP $\gamma$-S, a nonhydrolyzable analog of GTP that results in accumulation of the activated GTP-bound Spglp. This had no effect on the ability of mAb 12CA5 to immunoprecipitate Spg1HAp (Fig. 2D). However, addition of GTP $\gamma$-S reduced significantly the amount of Spglp precipitated by SuSul (Fig. 2E), indicating that the epitopes recognized by this antiserum are masked when Spglp is in the GTP-bound form. Assuming that the ability of the SuSul antiserum to recognize Spglp epitopes in fixed cells is affected the same way, the SuSul antiserum acts as a marker for the GDP-bound form of Spglp.

Using SuSu1, Spglp was only detected on one of the two spindle pole bodies both in cells undergoing anaphase $B$, and forming a division septum (Fig. 7A). Moreover, no Spglp staining was seen in cells with a short spindle (Fig. 7B), or in the nda3-KM 311 mutant (data not

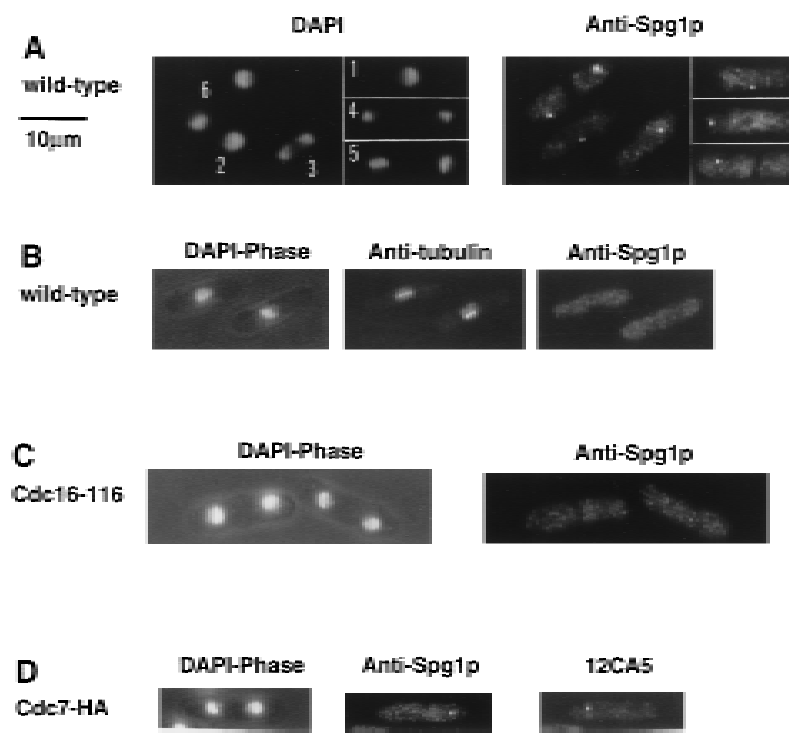

Figure 7. Localization of Spglp with an antibody recognizing the GDP-bound form of Spglp (SuSu1). Cells were grown at $25^{\circ} \mathrm{C}$ in $\mathrm{YE}$ and prepared for immunofluorescence, using the indicated antibodies. DAPI shows the DNA; phase contrast shows the cell outline. The antibodies used in each case are indicated. cdc16-116 cells were shifted to $32^{\circ} \mathrm{C}$ for $1.5 \mathrm{hr}$ before fixation. (A) Wild-type cells (972), stained with the anti-Spglp antiserum (SuSu1). Cells 1 and 2 are in interphase; cells 3 and 4 are undergoing anaphase B; cell 5 is forming a division septum; cell 6 has completed septum formation. (B) Early mitotic wildtype cells (972) stained with SuSul and TAT-1. (C) cdc16-116 cells stained with SuSu1. (D) Late mitotic cdc7-HA cell stained with SuSul and mAb 12CA5. shown), suggesting that Spglp is in the GTP-bound form on both poles early in mitosis. In cdc16-116 cells, where Spglp should be predominantly in the GTP-bound form and $C d c 7 p$ segregated to both poles during anaphase (Fig. $6 A$ ), GDP-Spglp could not be detected at any stage of mitosis using SuSul (Fig. 7C), though staining with $\mathrm{mAb}$ 12CA5 demonstrated that Spglp was present on both spindle pole bodies in this mutant (Fig. 6B). These data are consistent with the view that SuSul preferentially recognizes GDP-Spglp.

Staining of cdc7-HA cells with both mAb $12 \mathrm{CA} 5$ and SuSul showed that Cdc7p and inactive Spglp never colocalized on the same spindle pole in 250 late mitotic cells analyzed (Fig. 7D). This finding is consistent with the observation that $\mathrm{Cdc} 7 \mathrm{p}$ interacts preferentially with GTP-Spglp (see Fig. 2B). Staining of germinating cdc7 null cells with SuSul showed asymmetric distribution of GTP-bound Spglp staining even in the absence of C dc7p (Fig. 5B). Thus, inactivation of Spglp on one pol e early in anaphase does not depend on the activity of Cdc7p. The localization of Cdc7p and the GTP- and GDP-bound forms of Spglp are summarized in Figure 8A. Together with the in vitro data shown in Figure $2 \mathrm{~B}$, these results suggest that the $C d c 7 p$ protein kinase localizes to the spindle pole body by interacting with the activated, GTP-bound form of Spglp and imply that this is a key step in priming the cell for septum formation.

\section{Discussion \\ Spindle pole body location of inducers of septum formation}

In this paper we have demonstrated that the Cdc7p kinase and the Spglp GTPase, with which it interacts to induce septum formation, are associated with the spindle pole body and that C dc7p is local ized on only one spindle pole late in anaphase. At no stage in mitosis or septum formation have we observed an association of Spglp or Cdc7p with the medial ring. This result is unexpected, as it positions these key regulatory molecules far from the site where the septum will be synthesized. We believe that this may provide an important insight into how the link between the mitotic apparatus and the septum-forming machinery in fission yeast is established to ensure proper coordination of mitosis and cytokinesis. The $\mathrm{Cdc} 2 \mathrm{p} / \mathrm{Cdc} 13 \mathrm{p}$ kinase [the S. pombe equival ent of mitosis promoting factor (MPF)] and components of the $20 \mathrm{~S}$ cycl osome/ anaphase promoting complex (APC), local ize to the spindle pole body, or its mammalian equivalent, the centrosome (Alfa et al. 1990; Kalt and Schliwa 1993; Tugendrei ch et al. 1995). Colocalization of regulators of mitotic progression with components of the GTPase switch that is required for the onset of septum formation provides the potential for coordinating their activity during mitosis.

C dc7p may stand at the head of a GTPase-regulated protein kinase signal ing module (Schmidt et al . 1997). In its catalytic domain, $\mathrm{Cdc} 7 \mathrm{p}$ is most closely related to Saccharomyces cerevisiae STE11p, which is a member 


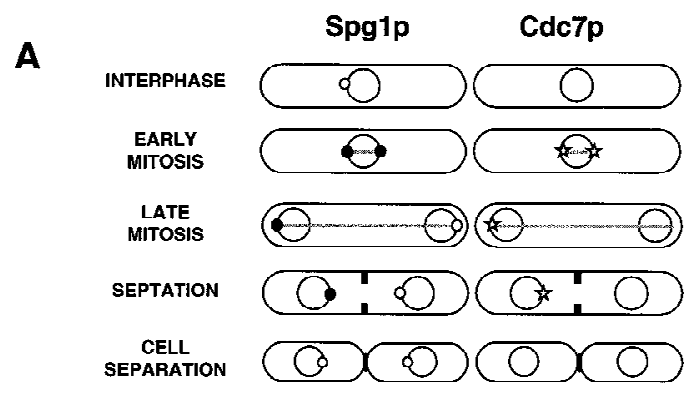

B

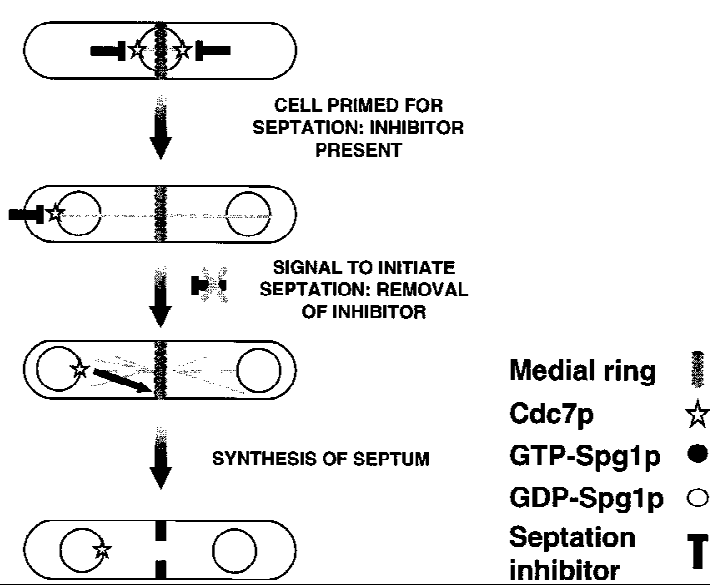

Figure 8. (A) Diagram showing the changes in localization of Cdc7p, Spglp, and GDP-Spglp during the cell cycle. N ote that while Spglp is al ways associated with the spindle pole body, it is predominantly in the GTP-bound form during mitosis. C dc7p is only associated with the spindle pole body during mitosis and is segregated asymmetrically during anaphase B. (B) The signal for the onset of septum formation is delivered from the spindle pole body. The diagram summarizes our working hypothesis. Activation of a Cdc7p-dependent signaling pathway at the end of anaphase sends a signal from the spindle pole body to the medial ring to initiate synthesis of the division septum. Because the cell is primed for septation from the beginning of mitosis, the presence of a putative inhibitor during early mitosis is indicated. The nature of the restraint of Cdc7p signaling in early mitosis is unknown at present. It may be mediated by altering substrate availability or inhibition of the spindle pole bodybound fraction of the enzyme. For further details, see Discussion.

of the mitogen-activated protein (MAP) kinase kinase kinase family (Fankhauser and Simanis 1994). In mammalian cells, activation of a M AP kinase signaling module is accompanied by changes in the subcellular localization of M AP kinase (Lenormand et al. 1993). By analogy with this, we propose that, at the end of mitosis, activation of a Spglp-Cdc7p-dependent signal transduction pathway sends a signal from the spindle pole body to the medial ring to trigger septum synthesis (shown schematically in Fig. 8B). Transfer of Cdc7p to one spindle pole during mitosis may ensure that the signal for the onset of septum formation will be given only from a single site. It is noteworthy that in all situations where septum formation is deregulated, Cdc7p is seen on both poles during mitosis. Identification and localization of the target(s) and proteins downstream of $\mathrm{Cdc} 7 \mathrm{p}$ will be of considerable interest.

Implications of these data for the regulation of septum formation

Kinase assays in vitro suggest that $\mathrm{Cdc} 7 \mathrm{p}$ has the potential to be active at all stages of the cell cycle. Assuming that this is an accurate reflection of the in vivo situation, the finding that Spglp is in the GTP-bound form and Cdc7p is al ready associated with the spindle poles early in mitosis, suggests that $\mathrm{Cdc7p/Spglp} \mathrm{is} \mathrm{prevented} \mathrm{from}$ signaling the onset of septum formation precociously during the early stages of mitosis. This could be achieved by making the key substrates unavailable, or unresponsive, to Cdc7p kinase activity until the end of mitosis, or by the presence of an inhibitor of $\mathrm{Cdc} 7 \mathrm{p}$ during mitosis. Removal of an inhibitor of C $\mathrm{dc} 7 \mathrm{p} / \mathrm{Spg} 1 \mathrm{p}$ (or changing substrate availability) at the end of mitosis would provide an excellent means of coordinating mitotic events with the onset of septum formation.

Increased expression of Spglp in interphase cells promotes medial ring and septum formation (Schmidt et al. 1997). This indicates that the key substrates of $C d c 7 p /$ Spglp are potentially available throughout the cell cycle and therefore suggests that the activity restraining septum formation during mitosis is absent during interphase. Consistent with this, induction of spgl expression does not induce septum formation in cells arrested in early mitosis by the nda3-KM 311 mutation (L. Ce rutti and V. Simanis, unpubl.), though it will do so in $\mathrm{G}_{1^{-}}$, S-, or $\mathrm{G}_{2^{-}}$arrested cells (Schmidt et al. 1997). Septation during interphase may therefore be restrained by regulating activation of Spglp.

It is noteworthy that inactivation of Cdc2p kinase in a mitotically arrested cell will bring about cytokinesis or septum formation in both $\mathrm{S}$. cerevisiae and $\mathrm{S}$. pombe (Ghiara et al. 1991; He et al. 1997). Moreover, mutants that arrest late in mitosis with elevated Cdc2p kinase activity do not undergo septum formation and cytokinesis (M oreno et al. 1989; Surana et al. 1993). It is therefore possible that the onset of septum formation is inhibited by high $\mathrm{Cdc} 2 \mathrm{p}$ kinase activity during mitosis. Studies of myosin II regulatory light chain phosphorylation in higher eukaryotes provide a precedent for Cdc2 $p$ inactivation in triggering cytokinesis. Myosin II regulatory light chain activity appears to be both negatively and positively regulated by changes in its phosphorylation state. During mitosis, it is inhibited through phosphorylation by Cdc2p/cycl in B (Satterwhite et al. 1992). When $\mathrm{Cdc} 2 \mathrm{p} / \mathrm{cycl}$ in B is inactivated in the normal cell cycle, coincident with the metaphase-anaphase transition, these phosphorylations no longer occur; and coincident with this, phosphorylation of another site by myosin light chain kinase is markedly increased (Yamakita et al. 1994). The changes at these phosphorylation sites are thought to contribute to signaling the initiation of cytokinesis.

The onset of anaphase and inactivation of Cdc2p/cy- 
clin B kinase is brought about by the proteolysis of key substrates targeted by the anaphase-promoting complex (APC). The finding that some cut mutants encode components of the APC (Y amashita et al . 1996; Y amada et al . 1997) argues that the putative inhibitor of septation may not be removed by APC-mediated proteolysis. However, increased expression of the APC component Nuc2p bl ocks septation but does not interfere with mitosis (Kumada et al. 1995). Clearly, future studies will address how Cdc7p/Spglp signaling is activated at the end of mitosis and whether the APC plays a role in this signaling.

What mediates the asymmetrical distribution of Cdc7p on the spindle poles during anaphase?

Electron microscopic observation shows that it is highly likely that two apparently identical daughter spindle pole bodies arise by the splitting of a single precursor in S. pombe (Ding et al. 1997). Our data clearly indicate that the two daughter pole bodies produced by this apparently symmetrical structure are not identical.

In S. cerevisiae, a Karlp- $\beta$-galactosi dase fusion protein has been shown to localize predominantly to the cytoplasmic face of the new spindle pole body when expressed at high levels (Vallen et al. 1992). However, local ization of native Karlp demonstrated that it is present on the spindle pole body throughout the cell cycle and is a component of the bridge and half-bridge (Spang et al . 1995). The asymmetry observed in the earlier study was attributable to misdi rection of the Karlp- $\beta$-gal actosi dase fusion protein within the spindle pole body. Thus, our data represent the first example of asymmetric distribution of a native molecule on the spindle poles during mitosis. It is interesting to note that an example of nonequival ence in the centrioles of a higher eukaryote has been described recently (Lange and Gull 1995). The antibody marker called Cenexin is acquired by the immature centriole of the pair only at prophase: For the remainder of the cycle, only the mature centriole is Cenexin positive.

The nature of the signal that promotes the switch from bipolar to monopolar Cdc7p localization during anaphase is unknown: It may be attributable to progression past a mitotic checkpoint, or it might be a function of spindle length. The timing of the switch from bipolar to monopolar Cdc7p staining is similar to the timing of the disappearance of $\mathrm{Cdc} 2 \mathrm{p} / \mathrm{Cdc} 13 \mathrm{p}$ from the poles (Alfa et al. 1990). However, we do not know at present whether APC activity is required for the transition to monopolar Cdc7p localization. Since the disappearance of Cdc7p from one spindle pole correlates with inactivation of Spglp, and Cdc7p and GDP-Spglp never colocalize in late anaphase, we favor the view that Cdc7p is delocalized from one pole by asymmetric inactivation of Spglp. Because Spglp associates with both spindle pole bodies throughout mitosis, it seems likely that the factors regulating Spglp activity will be distributed, or regulated, asymmetrically on the spindle poles. Potential negative regulators of Spglp are Cdc16p (Fankhauser et al. 1993;
Schmidt et al. 1997), Byr4p (Song et al. 1996), and Dmalp (Murone and Simanis 1996). Their localization during mitosis will be of considerable interest.

Why does increased expression of cdc7, plo1, or spgl deregulate septum formation?

Plolp kinase is essential not only for formation of a bipolar spindle but also for septum formation: Ectopic expression of the protein can also trigger septum formation in interphase cells (Ohkura et al. 1995). Studies of PIk1, the human counterpart of plo1, have demonstrated that microinjection of neutralizing antibodies prevents centrosome maturation (Lane and N igg 1996). It is tempting to speculate that an untimely increase of Plolp kinase activity during interphase in S. pombe causes premature spindle pole body maturation and activation of Spglp. This could be achieved by negative regulation of Spglp inhibitors, recruitment of Spglp activators, or both. Because increases in Spglp activity can induce all stages of septum formation (Schmidt et al. 1997), this would explain the observed phenotypes of plol overexpression. It will be interesting to examine the localization of Spglp and Cdc7p in plol mutants, when they become available.

Previous work has shown that cells are very sensitive to increased spgl expression but much less so to increased cdc7 expression (Fankhauser and Simanis 1994; Schmidt et al. 1997). The finding that spindle pole body association of Cdc7p requires GTP-Spglp may offer an explanation for this apparent discrepancy. We have shown that Spglp is mostly GDP bound in interphase cells, so the tendency for Cdc7p to associate with the spindle pole body, where we presume its key substrates are localized, will be low. Thus, increased expression of Cdc7p will not induce septum formation in interphasearrested cells. In contrast, during mitosis, Spglp is GTPbound, and Cdc7p can associate with the spindle pole. It is possible that the excess of Cdc7p titrates away the putative negative regulator from the spindle pole body, giving deregulated signaling and multiple rounds of septum formation at the end of mitosis. Alternatively, it may hinder the inactivation of Spglp.

The spindle pole body/centrosome as an integrator of cell cycle events

Localization of key cell cycle regulators such as Cdc2p/ cyclin B (Bailley et al. 1989; Riabowol et al. 1989; Pockwinse et al. 1997) and polo-like kinases (Lane and Nigg 1996), to the poles of the spindle may explain the observation that isolated centrosomes parthenogenetically activate development in Xenopus, as they may provide a framework on which to build regulatory complexes (Tournier et al. 1989; Klotz et al. 1990). In S. pombe, the mitosis-inducing kinase $\mathrm{Cdc} 2 \mathrm{p} / \mathrm{Cdc} 13 \mathrm{p}$ is al so located on the spindl e pole body (Alfa et al . 1990). It is al so noteworthy that mutation of Cut12p, a spindle pole body component, is sufficient to circumvent the normal regulation of commitment to mitosis (A.J. Bridge, M. Mor- 
phew, R. Bartlett, and I.M. Hagan, in prep.). If the centrosome/spindle pole body acts as a scaffold and communication point through, and upon which, cell cycle pathways are coordinated, association of Cdc7p and Spglp, the "trigger" for septation, with the spindle pole body provides an excellent means of coordinating mitosis and cytokinesis.

\section{Materials and methods}

\section{Yeast techniques}

Standard techniques were used for growth, manipulation, and synchronization of fission yeast (M oreno et al. 1991). Cells were grown in yeast extract (YE) or EM M 2 minimal medium, supplemented as required. Other techniques have been referred to previously (Fankhauser et al. 1995). To generate synchronous cultures, cdc25-22 cdc7-HA cells were incubated for $4 \mathrm{hr}$ at $36^{\circ} \mathrm{C}$ and then released from the block by shifting them back to $25^{\circ} \mathrm{C}$ (M oreno et al. 1989). To examine germinating spores del eted for spgl or cdc7, the diploid strains heterozygous for either of the null alleles (Fankhauser and Simanis 1994; Schmidt et al. 1997) were induced to sporulate on malt extract plates (M oreno et al. 1991). Spores were prepared and inoculated in minimal medium containing adenine and leucine, so only the spores carrying the null allele could germinate and grow.

\section{Immunofluorescence}

Indirect immunofluorescence was performed as described previously (Sohrmann et al. 1996), except that cells were digested for $10 \mathrm{~min}$ in $1 \mathrm{mg} / \mathrm{ml}$ of Zymolyase 20T. The anti-Sadlp (Hagan and Yanagida 1995), anti-Cdc7p (Fankhauser and Simanis 1994), and anti-Spglp (SuSu1, Schmidt et al. 1997) antisera were affinity purified before use, according to standard procedures (Harlow and Lane 1988). The monoclonal anti-HA antibody (12CA5) was purchased from BabCO. The $\alpha$-tubulin mAb TAT-1 (Woods et al. 1989) was a generous gift from K. Gull (University of $M$ anchester). Specificity of the staining was confirmed by competition experiments with the antigen used to raise the antiserum (according to Sohrmann et al. 1996) and by staining of germinating spores deleted for either cdc7 or spgl. The epitopes recognized by the anti-Cdc7p and anti-Spglp antisera and by mAb $12 C A 5$ are sensitive to glutaral dehyde. $N$ ote that fixation in the absence of glutaral dehyde only preserves the mitotic spindle but not the interphase microtubule array. Microtubules were depolymerized by incubating the cells on ice for 25 min before fixation, as described by Hagan and Yanagida (1995). Cells were observed with a Zeiss Axiophot microscope. Production of color images and confocal microscopy has been described (Hagan and Yanagida 1997; Sohrmann et al. 1996).

\section{Construction of the spgl-HA and the cdc7-GFP strains}

To construct spgl-HA, the carboxy-terminal half of the spgl gene was amplified by PCR using the oligonucleotides VS 135 (ATCAAAGAATGGTACCGTCAAGCTCG) and VS 151 (GAG GATCCTTAATCAGCGGCCGCTGTATTCCAA) and cloned into pDW232 (Weilguny et al. 1991). The triple HA tag (Tyers et al. 1992) was cloned into the $N$ otl site introduced by VS 151 just before the stop codon. The $\mathrm{ura}^{+}$gene and $2 \mathrm{~kb}$ of genomic sequence $3^{\prime}$ of the spgl coding sequence were cl oned behind the tag. The whole linear insert was transformed into a ura4D 18 strain. Stable uracil prototrophs were checked by Southern and
Western bl otting for correct replacement of the spgl gene by the tagged version.

The cdc7-GFP strain was constructed as the cdc7-HA strain described previously (Schmidt et al. 1997), except that the HA tag in the transformed linear fragment was replaced by an improved version of the Aequorea victoria GFP (S65T, F64L). All strains in which the tagged gene replaced the wild-type copy were indistinguishable from wild type.

Protein extracts, kinase assays, and immunoprecipitations

Total protein extracts were prepared as described previously (Sohrmann et al. 1996). Extracts of soluble proteins and kinase assays were performed according to Fankhauser and Simanis (1994), except that mAb 12CA5 was used for Western blot analysis, after immunoprecipitation with polyclonal antiCdc7p antiserum. To precipitate Spglp or Spgl-HAp, $5 \mu \mathrm{l}$ of affinity-purified anti-Spglp antiserum, or $1 \mu \mathrm{g}$ of mAb 12CA5, respectively, was added to protein extracts $(1.5 \mathrm{mg})$ prepared in the absence or presence of $0.6 \mathrm{mM}$ GTP $\gamma \mathrm{S}$ (Sigma) and incubated for $60 \mathrm{~min}$ at $4^{\circ} \mathrm{C}$. The complexes were then precipitated using protein A-Sepharose (Sigma) and analyzed by Western blotting using the same antibody as for the immunoprecipitation.

\section{Association of Cdc7p and GST-Spglp}

The spgl gene was cloned into pGEX-3X (Pharmacia) and expressed in E. coli DH $5 \alpha$. The fusion protein was purified on a glutathione-Sepharose 4B (Sigma) column as described (Jacquet et al. 1994). Glutathione was removed by dialysis. For the GDP/ GTP exchange, $2 \mathrm{~mm}$ EDTA and $1 \mathrm{~mm}$ GTP $\gamma \mathrm{S}$ were added to the buffer. To examine the association between Cdc7p and Spglp, $0.5 \mu \mathrm{g}$ of GST, GDP-bound Spglp, or GTP-bound Spglp was incubated with $3 \mathrm{mg}$ of protein extract for $60 \mathrm{~min}$ at $4^{\circ} \mathrm{C}$. The GST-Spglp fusion protein and any bound proteins were collected by affinity chromatography on glutathione-Sepharose and analyzed by Western blotting.

\section{Acknowledgments}

We thank Lorenzo Cerutti for the gift of purified GST-Spglp fusion protein. We are grateful to Bruno Amati, Nicola Beltraminelli, Lorenzo Cerutti, Christian Fankhauser, Xavier LeGoff, $M$ atthias Peter, and Suzan Utzig, for discussions and comments on the paper. We are also grateful to Elena Cano for technical assistance. This work was supported by ISREC, the Swiss $\mathrm{Na}$ tional Science Foundation, the Swiss Cancer League, the Cancer Research Campaign (CRC), and a short-term European M olecuIar Biology Organization (EMBO) fellowship to M.S.

The publication costs of this article were defrayed in part by payment of page charges. This article must therefore be hereby marked "advertisement" in accordance with 18 USC section 1734 solely to indicate this fact.

\section{References}

Alfa, C.E., B. Ducommun, D. Beach, and J.S. Hyams. 1990. Distinct nuclear and spindle pole body population of cyclin-cdc2 in fission yeast. Nature 347: 680-682.

Bailly, E., M. Doree, P. N urse, and M. Bornens. 1989. p34 cdc2 is located in both nucleus and cytoplasm; part is centrosomally associated at G2/M and enters vesicles at anaphase. EMBO J. 8: 3985-3995.

Bal asubramanian, M.K., A. Feoktistova, D. McCollum, and K.L. Gould. 1996. Fission yeast Sop2p: A novel and evolutionarily 
conserved protein that interacts with Arp3p and modulates profilin function. EMBO J. 15: 6426-6437.

Boguski, M.S. and F. M cCormick. 1993. Proteins regulating Ras and its relatives. Nature 366: 643-654.

Chang, F., A. Woollard, and P. N urse. 1996. Isolation and characterization of fission yeast mutants defective in the assembly and placement of the contractile actin ring. J. Cell Sci. 109: 131-142.

Ding, R., R.R. West, M. M orphew, and J.R. M clntosh. 1997. The spindle pole body of Schizosaccharomyces pombe enters and leaves the nuclear envel ope as the cell cycle proceeds. Mol. Biol. Cell 8: 1461-1479.

Fankhauser, C. and V. Simanis. 1993. The Schizosaccharomyces pombe cdc14 gene is required for septum formation and can al so inhibit nuclear division. Mol. Biol. Cell 4: 531-539.

- - . 1994. The cdc7 protein kinase is a dosage dependent regulator of septum formation in fission yeast. EMBO J. 13: 3011-3019.

Fankhauser, C., J. Marks, A. Reymond, and V. Simanis. 1993. The S. pombe cdc16 gene is required both for maintenance of p34 ${ }^{\text {cdc2 }}$ kinase activity and regulation of septum formation: A link between mitosis and cytokinesis? EMBO J. 12: 26972704.

Fankhauser, C., A. Reymond, L. Cerutti, S. Utzig, K. Hofmann, and V. Simanis. 1995. The S. pombe cdc15 gene is a key element in the reorganization of F-actin at mitosis. Cell 82: 435-444.

Ghiara, J.B., H.E. Richardson, K. Sugimoto, M. Henze, D.J. Lew, C. Wittenberg, and S.I. Reed. 1991. A cyclin B homolog in S. cerevisiae; Chronic activation of the $\mathrm{Cdc} 28$ protein kinase by cyclin prevents exit from mitosis. Cell 65: 163-174.

Gould, K.L. and V. Simanis. 1997. The control of septum formation in fission yeast. Genes \& Dev. 11: 2939-2951.

Hagan, I.M., K. Gull, and D.M. Glover. 1997. Poles apart? Spindle pole bodies and centrosomes differ in ultrastructure yet their function and regulation is conserved. In Mechanisms of cell division-Frontiers in cell biology (ed. S. Endow and D.M. Glover), IRL Press, Oxford, UK. (In press).

Hagan, I.M. and J.S. Hyams. 1988. The use of cell division cycle mutants to investigate the control of microtubule distribution in the fission yeast Schizosaccharomyces pombe. J. Cell Sci. 89: 343-357.

Hagen, I. and M. Yanagida. 1995. The product of the spindle formation gene $\operatorname{sad}^{+}$associates with the fission yeast spindle pole body and is essential for viability. J. Cell Biol. 129: 1033-1047.

- - - 1997. Evidence of a cell cycle specific, spindle pole body mediated, nuclear positioning in fission yeast. J. Cell Sci. 110: 1851-1866.

Hall, A. 1994. A biochemical function for ras-at last. Science 264: 1413-1414.

Harlow, E. and E. Lane. 1988. A ntibodies: A laboratory manual. Cold Spring Harbor Laboratory Press, Cold Spring Harbor, NY.

He, X., T.E. Patterson, and S. Sazer. 1997. The S. pombe spindle checkpoint protein mad2p blocks anaphase and genetically interacts with the APC. Proc. Natl. Acad. Sci. 94: 7965-7970.

Hirano, T., S. Funahashi, T. U emura, and M. Yanagida. 1986. Isolation and characterization of Schizosaccharomyces pombe cut mutants that block nuclear division but not cytokinesis. EMBO J. 5: 2973-2979.

Hiraoka, Y., T. Toda, and M. Y anagida. 1984. The NDA 3 gene of fission yeast encodes $\beta$-tubulin: A cold-sensitive nda3 mutation reversibly blocks spindle formation and chromosome movement in mitosis. Cell 39: 349-358.
Jacquet, E., M.C. Parrini, A. Bernardi, E. Martegani, and A. Parmeggiani. 1994. Properties of the catalytic domain of CDC25, a Saccharomyces cerevisiae GDP/GTP exchange factor: Comparison of its activity on full-length and C-terminal truncated RAS2 proteins. Biochem. Biophys. Res. Commun. 199: 497-503.

Kalt, A. and M. Schliwa. 1993. Molecular components of the centrosome. Trends Cell. Biol. 3: 118-128.

Klotz, C., M.C. Dabauvalle, M. Paintrand, T. Weber, M. Bornens, and E. Karsenti. 1990. Parthenogenesis in Xenopus eggs requires centrosomal integrity. J. Cell Biol. 110: 405-415.

Kumada, K., S. Su, M. Yanagida, and T. Toda. 1995. Fission yeast TPR-family protein nuc2 is required for $\mathrm{G} 1$-arrest upon nitrogen starvation and is an inhibitor of septum formation. J. Cell Sci. 108: 895-905.

Lane, H.A. and E.A. Nigg. 1996. Antibody microinjection reveal $s$ an essential role for human polo-like kinase 1 (PIk1) in the functional maturation of mitotic centrosomes. J. Cell Biol. 135: 1701-1713.

Lange, B.M . and K. Gull. 1995. A molecular marker for centriole maturation in the mammalian cell cycle. J. Cell Biol. 130: 919-927.

Leberer, E., C. Wu, T. Leeuw, A. Fourest-Lieuvin, J.E. Segall, and D.Y. Thomas. 1997. Functional characterization of the Cdc42p binding domain of yeast Ste20p protein kinase. EMBO J. 16: 83-97.

Lenormand, P., C. Sardet, G. Pages, G. L'A Hemain, A. Brunet, and J. Pouyssegur. 1993. Growth factors induce nuclear transl ocation of MAP kinases ( $p 42^{\text {mapk }}$ and $p 44^{\text {mapk }}$ ) but not of their activator MAP kinase kinase ( $\left.p 45^{\text {mapkk}}\right)$ in fibroblasts. J. Cell Biol. 122: 1079-1088.

Marks, J. and J.S. Hyams. 1985. Localization of F-actin through the cell division cycle of Schizosaccharomyces pombe. Eur. J. Cell Biol. 39: 27-32.

Minet, M., P. Nurse, P. Thuriaux, and J.M. Mitchison. 1979. Uncontrolled septation in a cell division cycle mutant of the fission yeast Schizosaccharomyces pombe. J. Bacteriol. 137: 440-446.

Mitchison, J.M . and P. N urse. 1985. Growth in cell length in the fission yeast Schizosaccharomyces pombe. J. Cell Sci. 75: 357-376.

Mochly-Rosen, D. 1995. Localization of protein kinases by anchoring proteins: A theme in signal transduction. Science 268: 247-251.

M oreno, S., J. Haynes, and P. N urse. 1989. Regulation of p34 $4^{\text {cdc2 }}$ protein kinase during mitosis. Cell 58: 361-372.

Moreno, S., A. Klar, and P. Nurse. 1991. Molecular genetic analysis of fission yeast Schizosaccharomyces pombe. Methods Enzymol. 194: 795-823.

Murone, M. and V. Simanis. 1996. The fission yeast dmal gene is a component of the spindle assembly checkpoint, required to prevent septum formation and premature exit from mitosis if spindle function is compromised. EMBO J. 15: 66056616.

N urse, P., P. Thuriaux, and K. N asmyth. 1976. Genetic control of the cell division cycle in the fission yeast Schizosaccharomyces pombe. Mol. \& Gen. Genet. 146: 167-178.

Ohkura, H., I.M. Hagan, and D.M. Glover. 1995. The conserved Schizosaccharomyces pombe kinase plo1, required to form a bipolar spindle, the actin ring, and septum, can drive septum formation in $G_{1}$ and $G_{2}$ cells. Genes \& Dev. 9: 1059-1073.

Peter, M., A.M. Neiman, H.O. Park, M. van Lohuizen, and I. Herskowitz. 1996. Functional analysis of the interaction be tween the small GTP binding protein Cdc42 and the Ste20 protein kinase in yeast. EMBO J. 15: 7046-7059.

Pockwinse, S.M., G. Krockmalnic, S.J. Doxsey, J. N ickerson, J.B. 
Lian, A.J. van Wijnen, J.L. Stein, G.S. Stein, and S. Penman. 1997. Cell cycle independent interaction of CDC2 with the centrosome, which is associated with the nuclear matrixintermediate filament scaffold. Proc. Natl. Acad. Sci. 94: 3022-3027.

Riabowol, K., G. Draetta, L. Brizuela, D. Vandre, and D. Beach. 1989. The cdc2 kinase is a nuclear protein that is essential for mitosis in mammalian cells. Cell 57: 393-401.

Robinow, C.F. and J.S. Hyams. 1989. General cytology of fission yeast. In The molecular biology of the fission yeast (ed. A. Nasim, P.G. Young, and B.F. Johnson), pp. 273-331. Academic Press, N ew York, NY.

Satterwhite, L.L., M.J. Lohka, K.L. Wilson, T.Y. Scherson, L.J. Cisek, J.L. Corden, and T.D. Pollard. 1992. Phosphorylation of myosin-II regulatory light chain by cyclin-p34 ${ }^{\text {cdc2: A }}$ mechanism for the timing of cytokinesis. J. Cell Biol. 118: 595-605.

Schmidt, S., M. Sohrmann, K. Hofmann, A. Woollard, and V. Simanis. 1997. The Spglp GTPase is an essential, dosagedependent inducer of septum formation in Schizosaccharomyces pombe. Genes \& Dev. 11: 1519-1534.

Sohrmann, M., C. Fankhauser, C. Brodbeck, and V. Simanis. 1996. The $\mathrm{dmf} 1 / \mathrm{mid} 1$ gene is essential for correct positioning of the division septum in fission yeast. Genes \& Dev. 10: 2707-2719.

Song, K., K.E. Mach, C.Y. Chen, T. Reynolds, and C.F. Albright. 1996. A novel suppressor of rasl in fission yeast, byr4, is a dosage-dependent inhibitor of cytokinesis. J. Cell Biol. 133: 1307-1319.

Spang, A., I. Courtney, K. Grein, M. Matzner, and E. Schiebel. 1995. The Cdc31p-binding protein Karlp is a component of the half bridge of the yeast spindle pole body. J. Cell Biol. 128: 863-877.

Surana, U., A. Amon, C. Dowzer, J. McGrew, B. Byers, and K. N asmyth. 1993. Destruction of the Cdc28/CLB mitotic kinase is not required for the metaphase to anaphase transition in budding yeast. EMBO J. 12: 1969-1978.

Tournier, F., E. Karsenti, and M. Bornens. 1989. Parthenogenesis in Xenopus eggs injected with centrosomes from synchronized human lymphoid cells. Dev. Biol. 136: 321-329.

Tugendreich, S., J. Tomkiel, W. Earnshaw, and P. Hieter. 1995. $\mathrm{CDC} 27 \mathrm{Hs}$ colocalizes with $\mathrm{CDC} 16 \mathrm{Hs}$ to the centrosome and mitotic spindle and is essential for the metaphase to anaphase transition. Cell 81: 261-268.

Tyers, M., G. Tokiwa, R. N ash, and B. Futcher. 1992. The CIn3$\mathrm{Cdc} 28$ kinase complex of $\mathrm{S}$. cerevisiae is regulated by proteolysis and phosphorylation. EMBO J. 11: 1773-1784.

Vallen, E.A., T.Y. Scherson, T. Roberts, K. van Zee, and M.D. Rose. 1992. Asymmetric mitotic segregation of the yeast spindle pole body. Cell 69: 505-515.

Weilguny, D., M. Praetorius, A. Carr, R. Egel, and O. Nielsen. 1991. N ew vectors in fission yeast: Application for cloning the his2 gene. Gene 99: 47-54.

Woods, A., T. Sherwin, R. Sasse, T.H. MacRae, A.J. Baines, and K. Gull. 1989. Definition of individual components within the cytoskeleton of Trypanosoma brucei by a library of monoclonal antibodies. J. Cell Sci. 93: 491-500.

Yamada, H., K. Kumada, and M. Yanagida. 1997. Distinct subunit functions and cell cycle regulated phosphorylation of 20S APC / cycl osome required for anaphase in fission yeast. J. Cell Sci. 110: 1793-1804.

Yamakita, Y., S. Yamashiro, and F. Matsumura. 1994. In vivo phosphorylation of regulatory light chain of myosin II during mitosis of cultured cells. J. Cell Biol. 124: 129-137.

Yamashita, Y.M., Y. Nakaseko, I. Samejima, K. Kumada, H. Yamada, D. Michaelson, and M. Yanagida. 1996. 20S cyclo- some complex formation and proteolytic activity inhibited by the CAMP/PKA pathway. Nature 384: 276-279.

Yanagida, M. 1996. 20S cyclosome complex formation and proteolytic activity inhibited by the CAM P/PKA pathway. Nature 384: 276-279. 


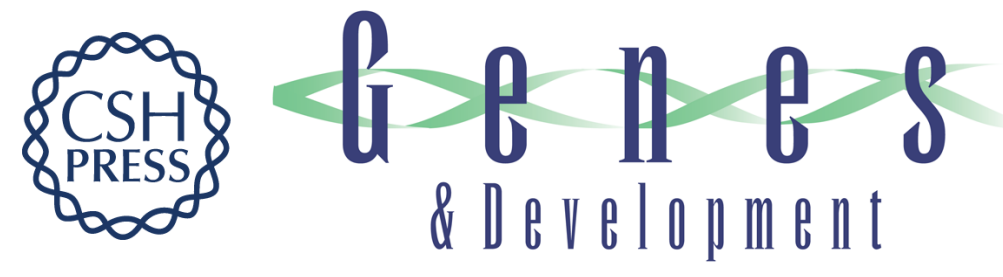

\section{Asymmetric segregation on spindle poles of the Schizosaccharomyces pombe septum-inducing protein kinase Cdc7p}

Marc Sohrmann, Susanne Schmidt, lain Hagan, et al.

Genes Dev. 1998, 12:

Access the most recent version at doi:10.1101/gad.12.1.84

$\begin{array}{ll}\text { References } & \begin{array}{l}\text { This article cites } 54 \text { articles, } 28 \text { of which can be accessed free at: } \\ \text { http://genesdev.cshlp.org/content/12/1/84.full.html\#ref-list-1 }\end{array}\end{array}$

License

Email Alerting Receive free email alerts when new articles cite this article - sign up in the box at the top Service right corner of the article or click here.

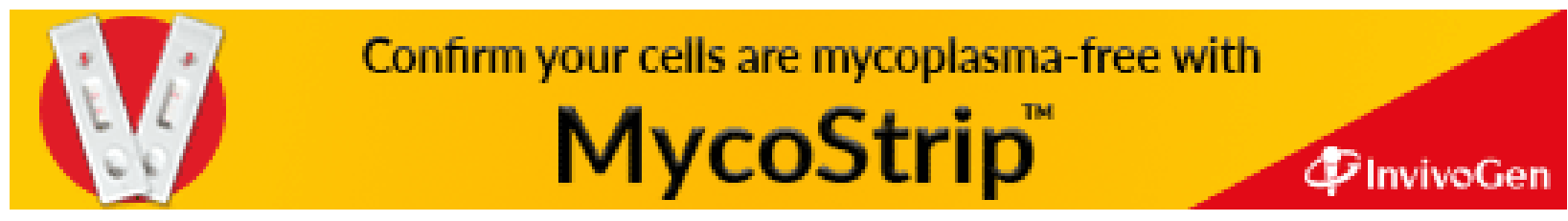

